\title{
O Uso da Estratégia Gameficação na Educação Médica
}

\section{The Use of Gamefication Strategy in Medical Education}

\author{
José Hícaro Hellano Gonçalves Lima Paival \\ Levi Coelho Maia Barros ${ }^{l}$ \\ Samuel Frota Cunhal \\ Tacilla Hanny de Sousa Andrade \\ Daniel Bezerra de Castro
}

\section{PALAVRAS-CHAVE}

- Educação Médica.

- Metodologia.

- Estudantes.
Introdução: $O$ ensino por meio de metodologia ativa vem ganhando cada vez mais destaque no cenário da educação médica, complementando, ou mesmo substituindo, o método de ensino tradicional. Diante disso, o sistema de gameficação, bem aceito por estudantes, inova, uma vez que o aprendizado se torna lúdico e participativo, contribuindo para a formação holística dos acadêmicos. Objetivos: Descrever a realização de uma gincana - composta por quatro fases e de caráter competitivo -, bem como comprovar a eficácia do método como uma forma inovadora de aprendizagem. Ao todo, 16 acadêmicos de Medicina participaram da gincana. Metodologia: Caracteriza-se como um estudo de delineamento observacional transversal, com uso de metodologias quantitativas e qualitativas. O estudo é composto pela aplicação de um método de ensino e aprendizado baseado no processo de gameficação, com posterior aplicação de um questionário avaliativo aos alunos, para análise crítica. Resultados: Foi observada satisfação dos alunos quanto à atividade, sendo unânime a afirmação de que a técnica utilizada facilita o aprendizado. Entre os integrantes, $87,5 \%$ preferiram a aplicação de práticas de metodologias ativas em detrimento das tradicionais, e $81,25 \%$ dos participantes apontaram a necessidade de integrar métodos com abordagens lúdicas às suas atividades curriculares. Por outro lado, $12,5 \%$ dos estudantes concordaram em que a atividade lúdica aplicada não contribui para o trabalho em equipe e 6,25\% preferiram adesão às práticas de metodologia tradicional. Conclusão: O método de gameficação desenvolve um ambiente propício ao aprendizado, com grande adesão dos estudantes. Percebe-se também a necessidade de mudança, apoiada pelos alunos, nas formas de ensino utilizadas na graduação, devendo-se buscar metodologias que abranjam o desenvolvimento de múltiplas competências e que possam usar a ludicidade como atrativo para o processo de aprendizado. 


\section{KEY-WORDS}

- Medical Education.

- Methods.

- Students.

Recebido em: 4/9/2018

Aceito em: 17/9/2018

\section{ABSTRACT}

Introduction: Education through active methodology is increasingly gaining attention in the medical education scenario, complementing, or even replacing, the traditional teaching method. Bearing this in mind, the system of gamification, a well-accepted one among students, innovates, since the learning process becomes playful and participatory, contributing to the holistic formation of the students. Objectives: To describe the accomplishment of a four-round, competitive championship, and to prove the effectiveness of the method as an innovative form of learning. In all, 16 medical students participated in the championship. Methods: This was a cross-sectional, observational study, using quantitative and qualitative methodologies. The study consists of the application of a teaching and learning method based on the gamification process and the subsequent application of an evaluation questionnaire to the students for critical analysis. Results: Student satisfaction with the activity was observed, with the unanimous assertion that the technique used facilitates learning. $87.5 \%$ of the members preferred the application of active methodologies over traditional ones. $81.25 \%$ of the participants asserted the need to integrate methods with playful approaches into their curricular activities. On the other hand, $12.5 \%$ of the students agreed that the applied leisure activity does not corroborate for teamwork and $6.25 \%$ preferred the traditional teaching methods. Conclusion: It was demonstrated that the method of gamification develops a propitious environment for the learning process, with substantial student support. The requirement for change in the educational methods used in undergraduate training could also be perceived, as well as support for such changes among students, and hence the need to seek more and more methodologies that support the development of multiple competences and that can use playfulness as an incentive for the learning process.

\section{INTRODUÇÃO}

Desde meados do século $X X$, tem-se observado a necessidade crescente de mudança das abordagens metodológicas adotadas por profissionais médicos em todo o mundo, com o intuito de promover estudantes com uma formação generalista, humanista, crítica e resolutiva ${ }^{1}$. Assim, tornou-se necessário pensar em métodos de ensino-aprendizagem capazes de fomentar práticas libertadoras durante a formação de profissionais ativos e pensantes ${ }^{2}$.

Os modelos pedagógicos tradicionais são centrados no professor e em aulas expositivas, em que as disciplinas são dissociadas entre si, e priorizam a capacidade de memorização dos estudantes, o que colabora para formar profissionais passivos e acríticos. Nessa estratégia metodológica, existe um déficit na assimilação do conhecimento, haja vista sua dessincronização com a prática clínica. Portanto, notam-se nítidas desvantagens na adoção de modelos tradicionais nos cursos médicos, uma vez que, no exercício da medicina, é de suma importância que exista uma integração entre conhecimento e habilidades ${ }^{3}$.

Contudo, não se pode mais admitir uma forma de ensino em que a fonte de conhecimento se restrinja apenas ao profes- sor, uma vez que atualmente novas maneiras de disseminação de informação se mostram de fácil acesso por meio da internet. Portanto, métodos de ensino baseados na flexibilização dos métodos educacionais são necessários frente aos avanços técnico-educacionais da atualidade ${ }^{4}$.

Como alternativa ao ensino tradicional, surgem as metodologias ativas, centradas no aluno, que deve se apresentar como sujeito ativo do processo de aprendizado, sendo estimulado em uma formação crítica, resolutiva e colaborativa. Tais metodologias colaboram também para formar profissionais capazes de promover agregação de conhecimento e sua aplicabilidade frente aos menores e mais complexos problemas $^{5}$. Esse tipo de abordagem leva o estudante a "aprender a aprender"6.

Observando a eficácia e importância de um ensino dinâmico e ativo no processo de assimilação do conhecimento, várias escolas médicas vêm adotando essa forma de metodo$\operatorname{logia}^{2}$. Vale ressaltar que o ensino médico se mostra complexo, uma vez que deve buscar aliar a prática ao conhecimento adquirido, a fim de formar bons profissionais.

A metodologia pedagógica baseada na utilização de jogos - gamification - pode fomentar um melhor resultado edu- 
cacional. Embora mais estudos nessa área sejam necessários, sabe-se que jogos têm potencial para facilitar e aprimorar o processo de ensino-aprendizagem por meio de experiências ativas vivenciadas pelos participantes. No entanto, apesar de o processo competitivo estar intrinsecamente ligado aos jogos, ele não se resume apenas a isso, uma vez que a criação de um espaço colaborativo, divertido e capaz de garantir a aprendizagem é de vital importância para a eficácia do método ${ }^{7,8}$.

Ao aplicar o processo de gamification na área médica, o professor ou idealizador do projeto deve ponderar os potenciais benefícios da dinâmica com o tempo e esforços necessários a sua realização, devendo preconizar a estimulação de uma capacidade crítica, bem como a integração de diversão e emoção e redução de estresse/ansiedade. O idealizador do jogo pode colaborar para a formação de mentes "pensantes", com noções de ética e cidadania, independentemente dos resultados e vitoriosos ${ }^{7,8}$.

A implementação de um ensino dinâmico, sobretudo na área médica, é de vital importância para facilitar o processo de aprendizagem e a troca de informações entre os estudantes. Mais estudos são necessários para comprovar sua eficácia e motivar sua adoção por faculdades que empregam o ensino tradicional.

\section{OBJETIVO}

Este estudo tem como objetivo descrever a realização de uma gincana em uma universidade que adota metodologia de ensino baseada nos preceitos tradicionais. Busca-se também comprovar a eficácia do método como uma forma inovadora de disseminação do conhecimento, com posterior aplicação de um questionário avaliativo aos estudantes que dela participaram.

\section{MÉTODO}

Este estudo se caracteriza por um delineamento observacional transversal, com uso de metodologias quantitativas e qualitativas. O estudo é composto pela aplicação de um método de ensino e aprendizado baseado no processo de gameficação e posterior aplicação de um questionário avaliativo aos alunos.

\section{Etapas de aplicação do método}

\section{Sujeitos e local de aplicação do estudo}

O estudo foi composto por 16 acadêmicos do segundo, quarto e sexto períodos do curso de Medicina da Universidade Estadual do Ceará (Uece) e dois moderadores, também acadêmicos. O projeto foi de autoria dos membros da Liga de Clínica Médica (LCM), os quais estavam no mês do ciclo de ensino de Neurologia. Pelo interesse no assunto, a Liga de Neuroci- ências da Uece foi convidada a participar. Os moderadores iniciaram o estudo explicando aos demais participantes as regras, as pontuações e o questionário. O processo foi realizado no bloco acadêmico do curso de Medicina da Uece.

\section{Descrição do método}

Os participantes da gincana foram divididos em dois grupos, compostos por estudantes de diferentes semestres, distribuídos de forma igualitária - cada grupo recebia uma quantidade igual de acadêmicos de cada período, de tal forma que o conhecimento ficasse equilibrado. Os membros de cada grupo deveriam cooperar entre si a fim de que sua equipe conseguisse desenvolver uma boa discussão e obtivesse a vitória. Outros dois alunos, um de cada liga acadêmica, assumiram o papel de moderadores. Estes não participavam de nenhum dos grupos e deveriam, juntos, elaborar a construção da gincana e coordená-la.

Em suma, a gincana era composta por um caso clínico divido em quatro fases. O objetivo dos grupos era acertar o diagnóstico por meio do desenvolvimento de um raciocínio clínico eficaz para, assim, garantir a vitória. Entretanto, caso nenhum dos grupos conseguisse tal feito ou se empatassem, ganharia aquele que mais pontuasse durante a gincana. Essa pontuação era obtida por meio de acertos das perguntas que surgiam durante a fase de exposição dos exames complementares, e cada resposta correta corresponderia a um ponto. A vitória poderia ocorrer em qualquer uma das fases, a qualquer momento, desde que um dos grupos apontasse o diagnóstico correto.

FASE 1 - ANAMNESE E DISCUSSÃO: os moderadores apresentavam a parte inicial do quadro clínico, ou seja, anamnese e exame físico. Eram revelados, de maneira sequencial: identificação do paciente, queixa principal, história natural da doença, história patológica pregressa, história psicossocial, história familiar, hábitos de vida, interrogatório por órgãos e aparelhos e, por fim, o exame físico completo. Em seguida, eram concedidos dez minutos de discussão para que os membros de cada grupo debatessem entre si e tirassem dúvidas sobre o caso com os moderadores. Não eram permitidas consultas a nenhuma bibliografia, nem troca de discussão entre os grupos. Nessa fase não havia perguntas, portanto não haveria como pontuar. Contudo, caso uma das equipes chegasse a um diagnóstico, este já poderia ser dado, e, se correto, garantiria a vitória. Entretanto, caso a equipe errasse, perderia a quantidade de pontos igual à quantidade de perguntas que não foram respondidas. Assim, se o jogo possui dez perguntas que seriam feitas na Fase 2, a equipe ficaria com dez pontos negativos caso apontasse o diagnóstico errado nesta fase. O Anexo 1 apresenta um caso, a título de exemplificação. 
FASE 2 - EXAMES COMPLEMENTARES E PERGUNTAS: eram revelados os exames complementares do paciente. Porém, antes da exibição de cada exame, as equipes deveriam responder a uma pergunta. As perguntas eram de múltipla escolha (de A a E) e envolviam temas de clínica, anatomia, fisiologia, semiologia e patologia neurológica. Cada equipe recebia um minuto para chegar a um consenso sobre a resposta, e, assim que obtida a resposta ou tendo o tempo se esgotado, deveria levantar uma placa com o item da resposta simultaneamente. Caso a resposta fosse correta, a equipe ganharia um ponto. Caso incorreta, não haveria pontuação. Em seguida, era revelada a resposta correta sobre a questão e sua explicação, além de um dos exames complementares às duas equipes. Para cada caso clínico estavam disponíveis dez perguntas, e, portanto, dez exames complementares. Esses exames ajudavam as equipes na construção e na exclusão de hipóteses diagnósticas. O Anexo 2 apresenta dois exemplos de perguntas.

FASE 3 - DISCUSSÃO E DIAGNÓSTICO: aconteceria se nenhum dos grupos chegasse ao diagnóstico durante a segunda fase, quando a qualquer momento poderiam tê-lo dado. Nessa última fase, todas as informações do paciente já teriam sido reveladas. Os moderadores dariam cinco minutos para uma discussão final, e, por fim, cada grupo deveria apresentar a eles uma hipótese diagnóstica para o caso analisado, entregue de maneira escrita, confidencial e simultânea. A partir daí, era obtido o resultado final da gincana, e o vencedor seria conhecido. Em caso de empate, em que ambos os grupos acertassem ou errassem o diagnóstico, os pontos serviriam como critério de desempate.

FASE 4 - APLICAÇÃO DO QUESTIONÁRIO: na última etapa, foi aplicado um questionário avaliativo sobre a gincana e métodos de ensino e aprendizado, bem como estabelecidos temas de estudo individual para casa com base no que foi exposto em sala.

Cada caso durou 1 hora e 15 minutos, tendo sido aplicados dois casos clínicos. No primeiro, nenhum dos grupos acertou o diagnóstico (mixoma atrial). No segundo caso, um dos grupos, no final da terceira fase, acertou o diagnóstico (crioglobulinemia por hepatite C). O Anexo 3 apresenta, de forma esquematizada, os passos desse processo.

\section{Questionário avaliativo dos alunos}

O questionário (Anexo 4) era composto de oito itens, buscando saber a opinião dos participantes. Esse instrumento avaliava o processo aplicado naquele momento e também a possibilidade de aplicação de métodos de ensino-aprendizagem a longo prazo, em futuras aulas que cada um viesse a ministrar.
Também apreciava o quão efetivo seria o ensino por meio das atividades lúdicas que envolveram todos os participantes do início ao fim do estudo.

Os dados obtidos foram organizados no Microsoft Excel para posterior análise e sua disposição e discussão por meio de gráficos e tabelas.

\section{RESULTADOS}

Quanto à satisfação com a atividade, a média das notas foi de 9,106 , numa escala de 0 a 10. Foi unânime (100\%) a afirmação de que a técnica utilizada facilita o aprendizado com base em um projeto pedagógico dinâmico, quando comparada a atividades de ensino tradicional, bem como despertou o interesse dos alunos sobre os assuntos abordados. Em contrapartida, dois $(12,5 \%)$ dos 16 estudantes afirmaram que a atividade lúdica aplicada não colabora para o trabalho em grupo.

Em relação ao questionamento sobre a duração e o número de casos aplicados, $13(81,25 \%)$ participantes concordaram em que a quantidade e a distribuição de tempo da gincana foram pertinentes, não causando cansaço. No entanto, 1 (6,25\%) integrante afirmou que mais tempo deveria ter sido dedicado à gincana, com a consequente aplicação de maior número de casos, e 2 (12,5\%) afirmaram que a gincana se tornou cansativa.

Quando dada a opção de escolha entre a abordagem disciplinar tradicional e a metodologia utilizada, 14 (87,5\%) integrantes optaram pela aplicação de práticas de metodologias ativas, $1(6,25 \%)$ optou por adesão às práticas de metodologia tradicional e $1(6,25 \%)$ integrante sugeriu que houvesse uma mescla entre as duas abordagens disciplinares.

Quando questionados acerca da possível incorporação de metodologias ativas em suas futuras aulas ministradas, seja como futuros docentes ou em aulas de monitorias ainda durante a graduação, $13(81,25 \%)$ membros afirmaram a necessidade de integrar essa forma de abordagem lúdica às suas atividades curriculares, sendo que 2 (12,5\%) membros reafirmaram a necessidade de aglutinação entre as metodologias tradicional e ativa em suas práticas. No entanto, apenas 1 (6,25\%) integrante afirmou que não pretende fazer uso dessa forma de ensino-aprendizagem, seja em aulas de monitorias que venham a ser ministradas ou caso queira seguir a docência.

Por fim, um espaço para comentários e sugestões foi cedido aos participantes, sendo alguns dos comentários expostos no Anexo 5.

\section{DISCUSSÃO}

A incorporação de novos modelos educacionais no ensino médico é de vital importância na formação de profissionais, uma vez que contribui para a autonomia do estudante e sua capaci- 
tação nas melhores estratégias a serem adotadas na resolução de determinados problemas ${ }^{9,10}$. Os educadores médicos têm empreendido esforços na tentativa de modificar e melhorar a educação médica. No entanto, esse processo tem se mostrado complexo, uma vez que interfere na estrutura de poder já alicerçada na graduação ${ }^{9}$. Este estudo mostra um método alternativo e inovador de ensino da medicina que não é centrado no professor, mas, sim, em um processo de intercâmbio de ideias entre os alunos.

Vale ressaltar que a presença de um professor como moderador seria importante para sanar eventuais dúvidas durante o processo, apesar da inviabilidade da presença de algum docente durante a atividade. No entanto, essa ausência pode ser sanada com moderadores que tenham se preparado tendo por base estudos prévios dos temas abordados, colaborando para uma discussão inteligente e sem queda de produtividade.

\section{A qualidade da atividade}

Quanto ao número de casos discutidos e ao tempo de duração de todo o processo avaliativo, uma parcela significativa dos estudantes concordou em que os temas, tempo de discussão e quantidade de casos foram pertinentes. Alguns sugeriram uma ampliação da dinâmica durante todo o mês, recomendando, ainda, abordar várias áreas da clínica médica.

Isto é importante no processo avaliativo, uma vez que mostra o êxito conseguido em estimular e motivar os estudantes com a implantação da gincana. Essa boa aceitação pode evidenciar o interesse dos participantes em relação aos temas abordados durante a atividade.

Apenas uma pequena parcela dos participantes - dois alunos - afirmou que a gincana se tornou cansativa. Dois fatos podem explicar essa opinião: alguns integrantes haviam tido pouco contato com as disciplinas de clínica médica e neurologia, o que acarretou menor entendimento dos conteúdos discutidos; os casos apresentados na gincana eram raros, o que torna o diagnóstico complexo.

Portanto, a aplicação de metodologias ativas e dinâmicas requer um aprimoramento da maturidade dos estudantes, a qual, muitas vezes, não está completa, havendo vários obstáculos estressantes ao longo do curso ${ }^{11,12,13}$.

$\mathrm{O}$ trabalho em equipe visa promover o alto desempenho dos participantes e fomentar a responsabilização dos alunos pela aquisição do próprio conhecimento por meio da troca de informações e também por um trabalho colaborativo entre seus membros. Vale ressaltar que o trabalho em equipe contribui para a formação de jovens capazes de tomar decisões sensatas, por meio de análise de raciocínio crítico individual e em equipe ${ }^{14}$.
O trabalho em equipe foi motivado durante a aplicação da atividade e se mostrou promissor, uma vez que a maioria dos estudantes afirmou que o ambiente propicia um espaço colaborativo para a troca de informações com estudantes mais experientes (veteranos), fomentando, também, o raciocínio crítico e clínico. Poucos estudantes consideraram a experiência negativa ou infrutífera. A investigação das razões por trás disso requer mais estudo. Essa opinião talvez se deva a eventos críticos ocorridos no grupo, como disputas internas e omissão de participação de alguns membros.

Sendo assim, é de vital importância que ocorra uma seleção intencional - como a que foi feita na presente atividade - de forma a equilibrar o nível de conhecimento dos participantes da gincana, por meio de equipes constituídas por indivíduos com características diferentes em relação a perfil acadêmico, pessoal e sociodemográfico (idade, sexo) ${ }^{14}$.

As atividades grupais durante a graduação médica buscam não apenas preencher lacunas existentes no processo de aquisição de conhecimento, como também contribuir para um processo de aprendizagem das relações humanas, uma vez que as convivências interpessoais instigadas durante sua formação irão auxiliar seu processo de amadurecimento social e profissional. À medida que a graduação progride, torna-se nítido que pouco adianta para o profissional ser dotado apenas de conhecimentos técnico-científicos, sem o auxílio de habilidades interpessoais e de trabalho em equipe, uma vez que estas serão rotineiramente utilizadas na convivência com professores, colegas e pacientes ${ }^{15}$.

Dessa forma, a atividade aplicada contribui não apenas para a formação de estudantes "pensantes", como também para o aprofundamento das habilidades de trabalho colaborativo, o que, sem dúvida, será preciso na vida profissional. No entanto, é necessário investigar melhor como esse processo ocorre.

\section{Os estudantes e a realização da atividade}

O fornecimento de feedback, seja por meio da aplicação de questionários, seja por métodos orais, foi considerado de vital importância em vários estudos na área da educação médica, uma vez que possibilita ajustes de parâmetros falhos e estimula o processo de aprendizagem ${ }^{16}$. No presente estudo, a avaliação do método de ensino-aprendizagem também é essencial, porque fomenta o aprimoramento da metodologia aplicada, possibilitando uma assimilação do conteúdo abordado de forma mais alicerçada. Optou-se por aplicar um questionário objetivo que sumarizasse os principais pontos abordados ao longo da atividade, sendo finalizado com um espaço aberto para observações que os acadêmicos achassem pertinentes. 
Para uma análise mais acurada da eficácia dessas práticas, seria ideal realizar um estudo comparativo entre esta metodologia e a tradicional. Contudo, concluímos que o questionário apresenta boa capacidade avaliativa da gincana e de práticas dinâmicas.

É importante destacar também que o ensino médico utiliza diversas formas de avaliação, podendo fazer uso de diversas metodologias, a fim de possibilitar melhor capacidade assimilativa dos estudantes. Segundo a visão dos acadêmicos a atividade aplicada é um projeto dinâmico, que apresentou boa aceitação e fomenta um espaço de discussão em equipe de maneira motivadora e livre de julgamentos. Vale ressaltar que também contribui para rememorar conceitos que, muitas vezes, vão sendo esquecidos ao longo da graduação. A gincana é voltada ao aprimoramento do desempenho em equipe e individual e procura incentivar não apenas a construção de conhecimento, como também o desenvolvimento de habilidades como raciocínio crítico e trabalho em equipe.

Fronteiras entre jogos, atividades lúdicas e gincanas, como a aplicada no estudo, são muito permeáveis, permitindo uma interação entre elas. Contudo, devem-se implementar métodos de gameficação que visem não somente a um processo competitivo, mas também à cooperação entre os integrantes. No presente estudo, tentou-se conscientizar os participantes de que a atividade buscava incentivar o processo de raciocínio clínico de maneira dinâmica e colaborativa, e não apenas um processo avaliativo que se resumiria a repostas corretas e incorretas.

Uma opção para maximizar um processo colaborativo na dinâmica aplicada seria implementar casos que visassem não apenas ao diagnóstico, mas também a tratamentos que na prática pudessem ser modificadores de morbimortalidade. Para isto, uma conversa entre as equipes seria necessária nesse momento da gincana a fim de se chegar a uma abordagem terapêutica única ${ }^{17}$.

Contribuindo para solidificar um processo competitivo entre os estudantes, a dinâmica é valorizada e facilita o aprendizado dos conteúdos abordados, minimizando o desinteresse em participar $^{10}$.

Embora o número de sujeitos participantes do presente estudo seja pequeno, concluímos que o projeto tem capacidade para formar opinião acerca da aplicação de novos métodos de ensino na atualidade, bem como apresenta qualidade para ser aplicado em maior escala.

\section{Avaliação da aplicabilidade de metodologias ativas na graduação}

A aplicação de metodologias ativas no processo de ensino-aprendizagem é necessária na prática acadêmica por possi- bilitar uma tentativa de minimizar as carências observadas no ensino de graduação do curso de Medicina, sobretudo no que concerne à assimilação de conteúdos básicos, o que, muitas vezes, é feito de forma deficitária ${ }^{1}$. Contudo, apenas cinco participantes afirmaram que as disciplinas básicas ministradas na graduação não contribuíram significativamente para a discussão durante a atividade.

Tal fato pode ser explicado por um bom nível de conhecimento dos estudantes que participaram da gincana nas áreas abordadas (neurologia e clínica médica). E também por se tratar de uma pergunta bastante ampla ou pelos estudantes estarem satisfeitos com a metodologia adotada na graduação de sua instituição de ensino. Vale sublinhar que o ensino no curso de Medicina pode se valer de várias metodologias, que irão se adequar às necessidades estruturais da instituição de ensino superior ${ }^{18}$.

Considerável parcela dos participantes (93,75\%) concordou quanto à necessidade de adesão e à eficácia das práticas de metodologia ativa ou sua mescla com a tradicional no processo de ensino-aprendizagem. Afirmaram ainda a possibilidade de adoção dessas práticas em futuras aulas ministradas por eles seja em atividades de monitoria, seja numa possível carreira docente. Tal fato corrobora a solidificação do processo de ensino apoiado nessas técnicas, fomentando um trabalho interdisciplinar e a possibilidade de colocar em discussão problemas de saúde num contexto amplo e integrado ${ }^{19}$.

Contudo, a preferência por práticas de metodologia tradicional, como ocorreu no presente estudo por apenas uma pessoa, pode ser explicada por falhas no processo de aplicação da atividade lúdica - como pouco tempo para discussão, dificuldade já alicerçada no ensino, compreensão da neurologia e alta densidade dos conteúdos abordados -, que dificultaram a aceitação da metodologia. Esse dado pode ser mais bem compreendido quando observamos o processo histórico de ensino-aprendizagem desse estudante.

Em um estudo sobre a aprendizagem baseada em problemas com 12 estudantes do segundo ano da Faculdade de Medicina de Marília, a expectativa quanto à implantação de metodologias ativas foi negativa. Concluindo-se, o êxito da implantação de metodologias ativas e dinâmicas pode depender, em parte, dos recursos pessoais dos estudantes, como, por exemplo, de sua história prévia de aprendizagem.

\section{CONCLUSÃO}

O método aplicado mostrou-se motivador de um processo de ensino-aprendizagem dinâmico, uma vez que os estudantes e moderadores que participaram da gincana evidenciaram satisfação com a realização do projeto. Um ambiente propício à 
troca de informações entre os estudantes e um espaço para o crescimento crítico dos indivíduos foram desenvolvidos.

Devem-se estimular métodos semelhantes a esse, sobretudo em universidades que apresentem seus pilares de ensino alicerçados no método tradicional, a fim de incentivar o processo de ensino-aprendizagem por meio de atividades dinâmicas, como mostrado neste estudo e em outros aqui discutidos.

O emprego de práticas dinâmicas merece e necessita de maiores estudos, para que sua eficácia seja verdadeiramente comprovada, fomentando sua disseminação não apenas na área médica, como também em qualquer área de estudo.

\section{REFERÊNCIAS}

1. Soares SMS, Serapioni M, Caprara A. A Aprendizagem Baseada em Problemas na pós-graduação: a experiência do Curso de Gestores de Sistemas Locais de Saúde no Ceará. Rev Bras Educ Med. 2001;25:54-61.

2. Moreira A, Araújo A, Ribeiro A, Siqueira-Batista R. O Cenário Brasileiro. Rev Bras Educ Med. 2015;39(3):339-343.

3. Fasce E, Ramirez L, Ibanez P. Results of a problem-based learning experience applied to first year medical students. Rev. Med. Chil. 1994; 122(1): 1257-62.

4. Lobo LC. Educação Médica nos Tempos Modernos. Rev Bras Educ Med. 2015;39(2):328-332.

5. Araújo I de M, Araújo R de CT, Grácio MCCCC. Avaliação do aproveitamento do aluno em Nefrologia : Estudo Comparativo entre o Método Expositivo Tradicional e o Método de Aprendizado Baseado em Problemas. Rev Bras Educ Med. 2001;25(3):44-55.

6. Barrows HS, Tamblym RM. Problem-based learning: an approach to medical education. New York: Springer Publishing Company; 1980.

7. Pitt MB, Borman-Shoap EC, Eppich WJ. Twelve tips for maximizing the effectiveness of game-based learning. Med Teach. 2015;37(November):1013-1017. doi:10.3109/014215 9X.2015.1020289.

8. Akl EA, Pretorius RW, Sackett K, Erdley WS, Bhoopathi PS, Alfarah Z, et al. The effect of educational games on medical students' learning outcomes: A systematic review: BEME Guide No 14. Med Teach. 2010;32(1):16-27. doi:10.3109/01421590903473969.

9. Angeli O, Loureiro S. A Aprendizagem Baseada em Problemas e os Recursos Adaptativos de Estudantes do Curso Médico. Rev Bras Educ Méd. 2002:32-41.

10. Farias PAM de, Martin AL de AR, Cristo CS. Aprendizagem Ativa na Educação em Saúde: Percurso Histórico e Aplicações. Rev bras educ méd. 2015;39(1):143-150. doi:10.1590/1981-52712015v39n1e00602014.
11. Millan LR. Assistência psicológica ao aluno da faculdade de medicina da USP. Ponto e vírgula, 1986; 8.

12. Giorgetti MF. Problemas do ensino nos cursos de graduação da USP. Mesa-redonda de 24 de outubro de 1990; encontro: problemas e perspectivas do ensino nos cursos de pós-graduação da USP Ribeirão Preto, 1990.

13. Borges MC, F Chachá SG, Quintana SM, Carlos Freitas LC, Lourdes Rodrigues M V. Problem-based learning. Med ( $R i$ beirão Preto). 2014;47(3):301-307. doi:10.1007/978-94-0179066-6_5.

14. Krug R de R, Vieira MSM, Maciel MV de A, Erdmann TF, Vieira FCF, Koch MC et al. O "Bê-Á-Bá" da Aprendizagem Baseada em Equipe. Rev Bras Educ Med. 2016;40(4):602-610. doi:10.1590/1981-52712015v40n4e00452015.

15. Colares A, Andrade S. Atividades grupais reflexivas com estudantes de Medicina. Rev Bras. 2008;33(1):101-114.

16. Franco CAG dos S, Franco RS, Santos VM dos, Uiema LA, Mendonça NB, Casanova AP, et al. OSCE para Competências de Comunicação Clínica e Profissionalismo: Relato de Experiência e Meta-Avaliação. Rev Bras Educ Med. 2015;39(3):9. doi:10.1590/1981-52712015v39n3e02832014.

17. Rocha PED, Silva KZ. TRANSFORMANDO JOGOS COMPETITIVOS EM COOPERATIVOS: ATIVIDADES DE ARTE EDUCAÇÃO AMBIENTAL NO PROGRAMA USP RECICLA. 2010.

18. Bustamante Z M, Carvajal H C, Gottlieb B B, Contreras P JE, Uribe M M, Melkonian T E, et al. Hacia un nuevo instrumento de evaluación en la carrera de Medicina.: Uso del método OSCE. Rev Med Chil [Internet]. 2000

19. Venturelli J. Médicas: Capacitação Docente Innovative Educational Programs at Medical. 2001.

20. O'rourke F, Dean N, Mouradian MS, Akhtar N, Shuaib A. Atrial myxoma as a cause of stroke: case report and discussion. Canadian Medical Association Journal. 2003;169(10):1049-51. 


\section{Anexo 1}

Caso 1

- IDENTIFICAÇÃO: JIJ, 48 anos, masculino, engenheiro civil, natural e procedente de Edmonton, Canadá, casado, evangélico, destro.

- FONTE DA HISTÓRIA / QUEIXA PRINCIPAL: Paciente e familiares/ "desorientação"

- HISTÓRIA DA DOENÇA ATUAL: Acompanhantes relatam que paciente deu entrada no serviço de emergência do Hospital Geral de Edmonton após apresentar queda e alteração transitória do nível de consciência. A família nega incontinência urinária ou fecal e distúrbios do movimento.

- HISTÓRIA PATOLÓGICA PREGRESSA: Nega hipertensão, diabetes, dislipidemia e etilismo. Refere tabagismo desde os 20 anos. Nega alergias ou cirurgias prévias. Família refere que paciente fazia investigação no mesmo hospital para síncope (apresentou cinco episódios em um ano), associados à perda de peso de $20 \mathrm{~kg}$, mialgia e artralgias durante esse período. Familiares referem também perda de memória e mudanças de comportamento (agressividade, compulsão). Em uso de cloroquina e corticoides indicados pelo médico. Familiares referem que o médico suspeitou de "reumatismo" após FAN e c-ANCA positivos em baixos títulos. Não houve melhora do quadro em três semanas de início do tratamento.

- HISTÓRIA FAMILIAR: Nega histórico familiar de hipertensão, dislipidemia, demência, distúrbios psiquiátricos, doenças do colágeno, arritmias, infarto agudo do miocárdio, acidente vascular cerebral e epilepsia. Refere mãe com diabetes.

\section{- EXAME FÍSICO NEUROLÓGICO:}

- FUNÇÕES CORTICAIS SUPERIORES: rebaixamento do sensório (confusão), dificultando o exame das demais, paralisia facial central

- NERVOS CRANIANOS: pupilas isocóricas e fotorreagentes, musculatura ocular extrínseca +, paralisia facial central à esquerda, sensibilidade não testada, língua trófica sem desvio de palato.

- FORÇA E TÔNUS: força grau 3 em dimídio esquerdo e grau 5 em dimídio direito. Hipertonia à esquerda.

- REFLEXOS: reflexos grau 3 em dimidio esquerdo e grau 2 em dimídio direito. Sinal de Babinski à esquerda.

- SENSIBILIDADE e EQUILÍBRIO: Não testados.

Fonte: O'Rourke, Fintan et al. (2003) 20

\section{Anexo 2}

\section{Exemplo de questões aplicadas durante a gincana}

\section{Qual dessas patologias constituem síndromes epilépticas focais?}

a) Crise de ausência

b) Crise tônico-clônica generalizada

c) Crise mioclônica

d) Crise atônica

e) Crise da esclerose hipocampal

\section{O AVC pode gerar no ECG:}

a) Taquicardia sinusal

b) Bloqueio atrioventricular

c) Alargamento do intervalo QT

d) Ondas T invertidas difusamente

e) Supradesnivelamento de ST

Fonte: Elaborado pelos autores. 
Anexo 3

Etapas de aplicação do método

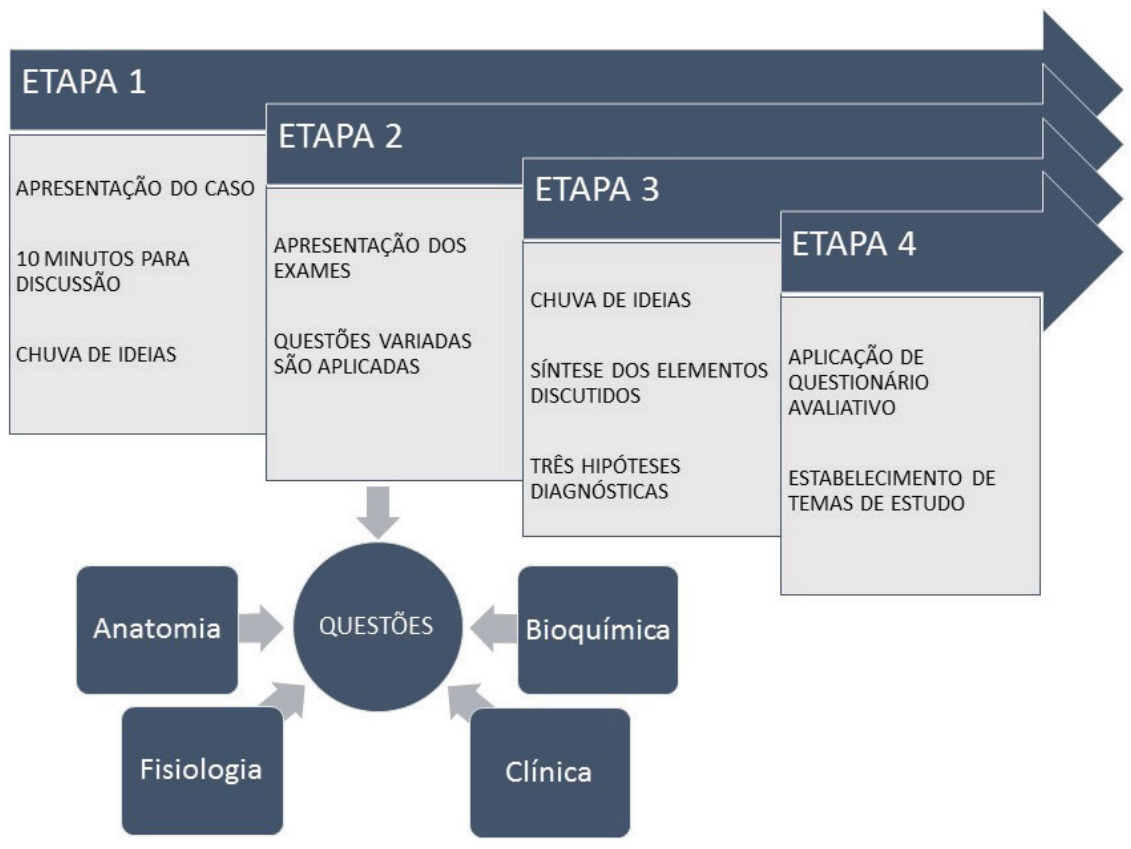

Fonte: Elaborado pelos autores.

\section{Anexo 4 \\ Questionário avaliativo}

Pergunta

Sim

Não

1. A técnica utilizada facilita o aprendizado quando comparada às aulas expositivas?

2. A técnica utilizada proporcionou o trabalho em equipe?

3. O método utilizado despertou interesse sobre assuntos antes desconhecidos por você e contribui significativamente para a aprendizagem do conteúdo abordado?

4. As disciplinas básicas ministradas na graduação contribuíram para a devida discussão durante os casos?

5. As técnicas de metodologias ativas deveriam e podem ser incorporadas à grade curricular da graduação?

6. A atividade teve duração e número de casos pertinentes, sem se tornar cansativa?

7. Você, como um possível docente ou monitor/orientador, se vê motivado a incorporar metodologias ativas em suas futuras aulas?

8. Se você pudesse escolher entre a metodologia tradicional e a metodologia ativa, qual metodologia elegeria como a melhor para assimilação do conteúdo?

Ativa

Tradicional

9. NOTA PARA A ATIVIDADE:

10. COMENTÁRIOS:

Fonte: Elaborado pelos autores. 


\section{Anexo 5}

\section{Comentários dos estudantes}

1. A1 - Excelente espaço para debate e aprendizado com os veteranos.

2. A2 - Deveria ser disponibilizado mais tempo para discussão dos casos entre os grupos. Mas a atividade foi bastante proveitosa e deveria ser feita mais vezes.

3. A1 e A3-A ideia deveria ser incorporada por outras ligas acadêmicas e também por professores.

4. A4-A gincana deveria durar não apenas uma tarde, mas, sim, um mês completo.

5. A1, A3, A4-Sem dúvida, a atividade ajudou a relembrar conhecimentos que vão sendo perdidos.

6. A5 - A atividade ajudou a entender melhor neurologia.

Fonte: Elaborado pelos autores.

\section{CONTRIBUIÇÃO DOS AUTORES}

José Hícaro Hellano Gonçalves Lima Paiva: Participou do planejamento do artigo, da coleta, análise e interpretação de dados, preparação de figuras e tabelas e escrita do artigo.

Levi Coelho Maia Barros: Participou da coleta, análise e interpretação de dados e escrita do artigo.

Samuel Frota Cunha: Participou da coleta, análise e interpretação de dados, preparação de figuras e escrita do artigo.

Tacilla Hanny de Sousa Andrade: Participou da coleta, análise e interpretação de dados e escrita do artigo.

Daniel Bezerra de Castro: Participou do planejamento do artigo e orientação dos estudantes do processo, da coleta, análise e interpretação de dados, escrita e revisão crítica do artigo.

\section{CONFLITO DE INTERESSES}

Nenhum dos autores do presente estudo apresenta conflito de interesses.

\section{ENDEREÇO PARA CORRESPONDÊNCIA}

Rua Barão de Aracati, Bairro Aldeota, 1430, ap. 1502 Aria, Fortaleza-CE, CEP: 60115-081. 